\title{
МЕТОДИЧЕСКОЕ ОБЕСПЕЧЕНИЕ УПРАВЛЕНИЯ ЧЕЛОВЕЧЕСКИМИ РЕСУРСАМИ В ПЕРИОД ПРЕОБРАЗОВАНИЯ ТРАДИЦИОННОЙ ОРГАНИЗАЦИИ В САМООБУЧАЮЩУЮСЯ
}

\author{
(c) 2020 Курячая Екатерина Анатольевна \\ Начальник отдела практической подготовки Учебно-методического управления. \\ Старший преподаватель. \\ Уральский государственный медицинский университет, Россия, Екатеринбург \\ Соискатель кафедры менеджмента, научной специальности 08.00.05 - Экономика и управление \\ народным хозяйством (менеджмент) (экономические науки) \\ Уральского государственного экономического университета \\ E-mail: eakuryachaya@mail.ru
}

В статье представлен действенный организационно-методический инструментарий управления человеческими ресурсами с конкретными и адаптированными методами организационных преобразований из традиционной в самообучающуюся организацию. Кроме того, предложен авторский механизм управления человеческими ресурсами, оказывающий существенное влияние на трансформацию традиционной организации в самообучающуюся.

Ключевые слова: самообучающаяся организация, управление человеческими ресурсами, механизмы самообучающейся организации, организационное обучение.

Введение. В настоящее время в контексте внедрения современных технологий, разработки и применения стандартов, выдвижения высоких требований к качеству товаров (услуг) и управления качеством необходимо изменение организационной модели и механизма управления человеческими ресурсами, позволяющими удержать высококвалифицированных специалистов, поддержать жизнеспособность организаций и способствовать стабилизации экономики страны.

В работах Армстронга М., Короткова Э.М., Кузнецова Ю.В. и других ученых человеческие ресурсы рассматриваются как работники, которые постоянно обучаются, развиваются, изменяются, инициируют и реализуют инновации, способствуя развитию жизненного цикла организации [5, с. 70-72].

Дафт Т. Ф., Гареев Т.Ф., Иващенко Н. С. и другие авторы определяют самообучающуюся организацию как организацию, которая постоянно развивается, используя знания, навыки, компетенции сотрудников, их способности для повышения эффективности организации и повышения ее конкурентоспособности [3, с. 16].

Теоретической основой для изучения феномена самообучающейся организации послужили классические и современные труды П.Ф.Друкера, П.Сенге, Р.Л.Дафта, М.Армстронга,
Т. Ф. Гареева, Ю.В. Кузнецова, Н.Ш.Епифановой, С.Р. Семушкиной, Н.И.Шаталовой, Г.Б. Кораблевой, В.И. Столярова и других ученых. Результаты работ этих авторов имеют только теоретическую направленность без конкретных и адаптированных методов создания самообучающейся организации и без полноценного организационнометодического инструментария для управления этапами развития самообучающейся организации, что послужило актуальностью исследований в данной области.

Методологической основой послужили теории менеджмента, организационного обучения, управления человеческими ресурсами, принципы андрагогики, проектный и командный подход к формированию организационных структур.

Для разработки и поэтапного внедрения комплексного механизма управления человеческими ресурсами при формировании самообучающейся организации применялись методы системного и процессного подхода к управлению человеческими ресурсами и управлению производственными процессами, факторный анализ, а также методы экономического, административного, социального и психологического управления в практической деятельности организации.

Теория и методика исследования базиру- 
ются на действующих документах, полученных статистических данных, результатах исследований и внедрений, которые были выполнены на базе организации отрасли здравоохранения. Исследуемая организация, является традиционной организацией, крупным экономическим объектом конгломератного типа, имеющая производственные и территориальные холдинги, диверсифицированные и специализированные сети с вертикально-интегрированной организационной структурой управления, находящейся в переходном периоде в самообучающуюся организацию. Для исследуемой организации характерны такие особенности, как наукоемкость, работоспособность в различных состояниях, включая экстремальные условия военных действий и чрезвычайных ситуаций, а также работоспособность одновременно в рыночной и нерыночной части.

Целью статьи является обоснование методического обеспечения действенной системы управления человеческими ресурсами в контексте преобразования традиционной организации в самообучающуюся организацию.

Методическое обеспечение этапов развития самообучающейся организации.

Для успешной реализации любых изменений в производственном процессе, жизненном цикле организации основным условием является поддержка руководителя высшего уровня управления, которая формируется только после практической демонстрации внедрения нововведений на уровне убеждений. Поэтому эффективное организационное развитие начинается с середины пирамиды управления как движущей силы перемен.

Основными этапами внедрения комплексного механизма управления человеческими ресурсами в период трансформации классической организации в самообучающуюся организационную модель является разработка и внедрение комплексного механизма управления человеческими ресурсами (рис.1).

В управления человеческими ресурсами эффективным управленческим инструментом, являющимся основой организационного механизма управления, является управление документооборотом.

Согласно результатам исследования, возрастает актуальность модернизации традиционной модели документооборота с использованием логического, виртуального, системного, стан- дартизованного и функционального научного подхода.

Социальная и экономическая обоснованность, перспективность и стандартизация включают в себя унифицированный состава и формы управленческих документов [1, с.149-153], предусматривающих реализацию однотипных управленческих функций и задач с целью сокращения количества используемых документов, дублирования одних и тех же данных и минимизации ошибок при ее ведении для повышения оценки эффективной деятельности персонала.

Основываясь на принципах целостности, структурности, иерархии, актуальности и взаимодействия с окружающей средой для высокой организации труда, совершенствования производственных процессов, культуры работы административного аппарата, оперативности, стандартизации, внедрения инноваций и использования информации в будущем, в организации создан механизм управления документационным обеспечением, ставшим основой реализации всех функций управления и производственных процессов.

Следующим этапом является создание системы организационного обучения, являющейся эффективной технологией развития компетенций, раскрытия способностей человеческих ресурсов, профилактики психоэмоционального выгорания, адаптации, мотивации, благоприятного взаимодействия в коллективе, действия в нестандартных ситуациях. Организационное обучение включает в себя два направления дополнительное непрерывное профессиональное образование специалистов (формальное, неформальное образование и самообразование) и корпоративное обучение на протяжении всей профессиональной деятельности, основанное на оценке потребностей организации и анализе ситуаций в нем [4, с. 115-123], связанного с системой управления человеческими ресурсами и организованного в виде комплексного непрерывного процесса развития профессиональных компетенций специалистов, построенных на разных организационных уровнях во всех аспектах их деятельности.

Комплексный анализ проведенного исследования подтверждает эффективность организационного обучения, позволяющим достичь высокой производительности труда при минимальных затратах, повысить качество и результативность его, улучшить корпоративную 


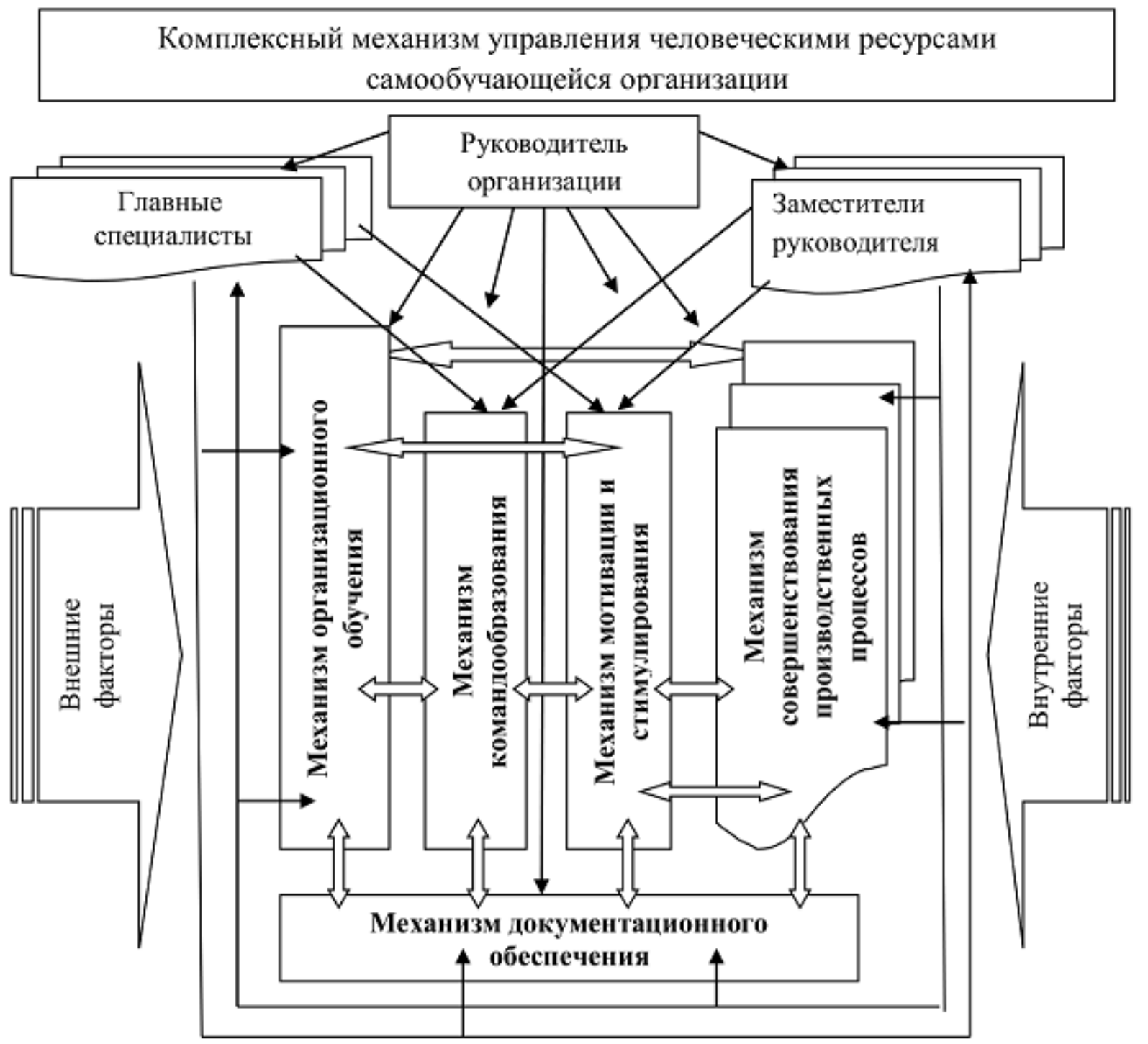

Puc. 1. Комплексный механизм управления человеческими ресурсами самообучающейся организации Примечание: Составлено автором.

культуру, снизить риск профессионального выгорания, внедрить инновации, сократить время адаптации новых сотрудников, укрепить трудовую дисциплину, снизить текучесть кадров, сформировать приверженность и лояльность сотрудников к организации и т.д.

Третьим этапом в реализации комплекса управления человеческими ресурсами при создании самообучающейся организации является разработка и внедрение системы формирования команд профессионалов. Основой организации команды экспертов является интеграция знаний, навыков и компетенций профессионалов в различных сферах деятельности [6, с. 1-11]. Синергетический эффект совместной деятельности персонала в командах позволяет достичь целей организации с минимальными затратами [7, с. 16-19], непрерывно совершенствовать производственные процессы, создавать и внедрять инновации, преодолевать устойчивость инноваций, разрабатывать альтернативные управленческие решения, эффективно управлять организацией в критических ситуациях.

Организационная структура профессионалов является ядром организации, в которой синергетический потенциал профессионалов создает новые идеи, внедряет новшества, развивает способности, таланты и компетенции сотрудников, обучает их, расширяя знания и навыки путем делегирования полномочий, создания матричной структуры управления, децентрализации управления и нивелирования сопротив- 
ления к нововведениям. Все это помогает продлить жизненный цикл организации.

Четвертым этапом является механизм управления системой мотивации и стимулирования деятельности персонала с использование процессного и системного подхода. Это важнейшая составляющая в управлении человеческими ресурсами для удовлетворения их потребностей с максимально возможной отдачей в достижении целей организации [2. с. 19-25].

Комплексная программа мотивации и стимулирования работы сотрудников представлена в таких разделах как материальные и нематериальные стимулы, социальные гарантии и санкции.

Созданная организационная система управления мотивациями и стимулами представляет собой взаимовыгодные социальноэкономические отношения между сотрудниками и организацией.

Заключающим этапом в управлении человеческими ресурсами самообучающейся организации является разработка ключевого ме- ханизма - непрерывного совершенствования производственных процессов. Эта важная фаза развития (совершенствования) производства, которая может быть достигнута только путем комплексного управления всеми вышеперечисленными инструментами.

Выводы. Представленное реализованное методическое обеспечение доказывает эффективность управления человеческими ресурсами в период формирования самообучающейся организации. Оно позволяет достичь положительных результатов с помощью организационнометодических инструментов эффективного управления человеческими ресурсами с минимальными затратами: эффективно управлять человеческими ресурсами; постоянно совершенствовать производственные процессы и внедрять инновации; создавать конкурентоспособные организации с длительным жизненным циклом, которые постоянно развиваются и своевременно реагируют на изменения внутренней и внешней среды, повышая ее эффективность.

\section{Библиографический список}

1. Анурина Т. М., Остахова Ю.А. Документационное обеспечение системы управления персоналом // Электронное информационное пространство для науки, образования, культуры: тезисы доклада VI Всероссийской конференции (Орел, 20 декабр.2018 г.). Орел, 2019. С. 149-153.

2. Егоркина Т.А. Гармонизация экономических интересов предприятия и его работников // Экономика и управление: теория и практика. 2020. Т.6. № 3. С. 19-25.

3. Гареев Т.Ф. Управление знаниями самообучающейся организации. Практическое руководство. М.: Издательские решения, 2016.

4. Девятовская И.В., КружковаО.В. Потенциал обучения взрослых для профилактики социальнопсихологической формы организационного вандализма // Педагогическое образование в России. 2020. № 1. С.115-123.

5. Иващенко Н. С. Самообучающиеся организации как фактор устойчивого развития организации // Перспективы развития науки и образования: тезисы доклада. Международной конференции (Москва, 30 ноябр. 2017 г.). Люберцы, 2017. С. 70-72.

6. Кулакова А.Б. Условия успеха командной работы в современной организации // Социальное пространство. 2020. T. 6. № 2. С.1-11.

7. Семенова М.А. Особенности командной работы при проектной деятельности организации // Научные записки ОРЕЛГИЭТ. 2020. № 1 (33). С.16-19. 